\title{
Vocational learning in a Swedish post-secondary apprenticeship
}

\author{
Magnus Fjellström ${ }^{*}$ (1)
}

\section{${ }^{*}$ Correspondence:}

magnus.fjellstrom@umu.se Department of Education,

Umeå University, Mediagränd

14, 90187 Umeå, Sweden

\begin{abstract}
Background: In Sweden, some occupations require post-secondary apprenticeship, e.g. those who are to become construction workers, while some do not, e.g. those who are to become business and administration workers. Research on post-secondary apprenticeship can be regarded as sparse. To address vocational learning in post-secondary apprenticeship, this explorative study focuses on apprentices in the construction industry. The aim of this study is to identify how vocational learning is constituted within workplace activities.
\end{abstract}

Methods: This study aimed to follow up a study of a former class of construction students who participated in project-based vocational education (Empir Res Vocat Educ Train 6:2, 2014). The study included 11 semi-structured interviews, which lasted between 35 and $55 \mathrm{~min}$, and a survey that related to 64 stated learning goals.

Result: The findings show that the development of vocational learning is closely linked to performing tasks that challenge the apprentices to think and solve problems. This approach to the performance of tasks enhances productive learning where the payroll system appears to trigger the scope of action. Further, this study shows that, despite differences in the activities that are carried out at different workplaces, the learning outcomes are dependent on personal goals as well as indirect and direct guidance.

Conclusion: Although stated learning goals are highly valued, the apprentices, have problems relating to them. Instead, interaction and guidance from more experienced co-workers lead to the development of a learning outcome. As described herein, a vocational learning outcome of post-secondary apprenticeships is complex, and can be understood as being related to individual goals and workplace activities that interact and constitute vocational learning. Thus, this explorative study has identified four main standpoints that afford vocational learning in post-secondary apprenticeship: (a) the importance of guidance in the workplace, (b) the possibility of performing complex tasks, (c) the encouragement to develop new methods, and (d) the possibility of being a part of the building process.

Keywords: Vocational education and training (VET), Construction worker, Guidance, Woodworker

\section{Introduction}

Working and learning can be viewed as a continuous activity (Billett 2001a) and, as argued in this article, a key concept that can be seen in an educational perspective. To

(c) The Author(s) 2017. This article is distributed under the terms of the Creative Commons Attribution 4.0 International License (http://creativecommons.org/licenses/by/4.0/), which permits unrestricted use, distribution, and reproduction in any medium, provided you give appropriate credit to the original author(s) and the source, provide a link to the Creative Commons license, and indicate if changes were made. 
further understand apprenticeship as an educational perspective, this article will focus on construction apprentices who have learning goals that are supposed to be reached while participating in workplace activities. As Klotz et al. (2014) state, "[v]ocational learning is a situated activity that takes place through a process of engagement in the sociocultural practices of the workplace" (p. 15). From this point of view, the concept of vocational learning can be seen as being developed by activities in a social setting. However, Billett (2001b) underlines the fact that learning through work is a constant ongoing activity and that work and learning are interdependent. Tynjälä (2013) also adds that learning within participation in workplace activities is often referred to as informal because there is no clear teaching agenda. Therefore, from her perspective, apprenticeship with learning goals, which can be viewed as formal, is taking an informal learning strategy approach. Nevertheless, Eraut (2009) argues that learning is closely connected to the context, which indicates that apprenticeships performed in different workplaces can be viewed as a unique form of education. Learning as an apprentice is shaped within the community of practice (Lave and Wenger 1991), and can be seen as being integrated into the specific workplace context by providing a "situative perspective" (Lyngsnes and Rismark 2011, p. 167). Understanding educational rationalities in work life is important and often associated with vocational practices (Billett 2009). Nevertheless, the post-secondary apprenticeship addressed in this study is surrounded by learning goals that are supposed to be reached by participating in different workplaces with different prerequisites.

On the basis of previous research that has mostly focused on learning at work (c.f. Billett 2001a; Ellström 2001), and learning through work (c.f. Billett 2009; Virtanen et al. 2012), it becomes clear that understanding educational perspectives of how a post-secondary apprenticeship, that is guided by learning goals, enables vocational learning. As stated by Klotz et al. (2014), p. 8, "An increasing body of research focuses on vocational learning as a component of individual efforts to contribute to work-related activities and interactions". Based on this approach, and that research regarding newcomers in a trade (Metso and Kianto 2014) is limited, an educational view of apprenticeship is not fully understood (Chan 2013). By addressing post-secondary apprenticeship, the aim of this study is to identify how vocational learning is constituted within workplace activities.

\section{Background}

In Sweden, some occupations do not need post-secondary apprenticeship, such as those who are to become business and administration or health care workers while those who are to become, for example, construction and electrical workers do need post-secondary apprenticeships. Subsequent apprenticeship that follows after graduation from the formal upper secondary school is in some way special as it is regulated by the trade union and the industry and not according to the Swedish government's definition of apprenticeship in upper secondary school (c.f. Berglund and Henning Loeb 2013, Berglund 2012).

To further understand vocational learning in post-secondary apprenticeship, this article will focus on apprentices who are to become woodworkers in the construction industry. The main way of becoming a construction worker involves both upper secondary vocational education in a construction programme and a subsequent apprenticeship i.e. 
post-secondary apprenticeship (c.f. Berglund and Lindberg 2012) through employment (SCITB 2013). This structure has long traditions (Berglund and Henning Loeb 2013), and, by participating in two work-based contexts, such as VET in school (cf. Fjellström 2014) and VET in the workplace as a subsequent apprenticeship, a jointly constructed objective for learning can be developed.

To become a professionally certified construction worker in Sweden, a successful completion of upper secondary vocational education in the occupation, and completion of mandatory time as an employed apprentice in the construction industry is required. The time spent as an apprentice can vary from person to person and is mainly dependent on two factors. The first is whether the individual has passed all courses in upper secondary school, and the second is whether he or she has worked during holidays before entering the apprenticeship. By completing all courses in upper secondary school, the apprentice is credited with $2800 \mathrm{~h}$, which are noted in an electronic education book provided by the national Swedish Construction Industry and Training Board (SCITB). After working a total of $6800 \mathrm{~h}$, including the credited hours from school, the apprentice becomes a professionally accredited construction worker.

During their apprenticeships, individuals are paid according to a five-step progression that is based on a percentage of the salary of a fully paid worker with a professional certificate. These stages are linked to the number of worked hours and are intended to correspond to their productivity. An apprentice with $2800 \mathrm{~h}$, that is, after upper secondary school, is placed in stage three and receives $65 \%$ of the regular salary. Stage four receives $75 \%$, and the final stage before a professional certificate is $88 \%$ of the regular salary.

This educational structure is guided and supported by three main documents: a "time sheet" that is included in the educational book, a "description of goals", and a "planning and follow-up" document that are provided by SCITB. The time sheet includes eight categories: formwork, framing and cladding, interior work, insulation, repair, reinforcement and concrete, and other. The time sheets are used by both the apprentices and their supervisors to document the number of hours that the apprentice completes in each category. The time sheet also acts as a record of hours to be added to the education book, either to advance a step on the payroll, or to apply for a professional certificate when the apprentice reaches $6800 \mathrm{~h}$. Accordingly, the link between the payroll system and the description of goals plays an important role in the educational structure as ticking hours in a time sheet will result in acquiring a professional certificate.

The description of goals consists of 64 goals that can be organised into 13 categories about which the apprentices are supposed either to have knowledge or be able to perform (i.e. know-how and know-what competencies). These are categorised as follows (1) construction documents, (2) tools and machines, (3) building material and outer environment, (4) building process, (5) building technique and calculations, (6) health and safety, (7) reinforcement, (8) facades, (9) interior work, (10) interior surface, (11) insulation, (12) frame completion, (13) frame and roofs.

The planning and follow-up document includes two sections. First is the planning section in which a specific educational strategy is documented and agreed between the participants (i.e. the apprentice and the assigned supervisor). Second, after approximately 6 months, the planning stage is followed up by evaluating how the educational strategy is working for the apprentice. Specifically, in this section, the apprentice is informed about 
how the development of competence is progressing. This process of follow-up and planning is repeated up to four times during the apprenticeship.

\section{Theoretical framework}

Based on individuals' engagement at work, and support and guidance provided in workplaces that constitute opportunities for workplace learning, the theoretical considerations in this article are based on aspects of a workplace curriculum (Billett 2001a) and learning levels (Ellström 2001). Learning within the workplace is often seen as informal (Aarkrog 2005; Billett 2013), while a Swedish post-secondary apprenticeship for construction workers involves reaching learning goals, thus qualifying as formal. To understand learning in the workplace, Billett (2001a) argues that the concept of a workplace curriculum comprises structured activities and guidance in the workplace which represents a structure that enables learners to move from being a novice to being a more skilled and legitimate worker. With respect to the structure of the learner's experiences, Billett (2001a) also argues that the structure of a workplace curriculum requires the following qualities: (a) the learners are to move from a low accountability to a high accountability situation, (b) the development of knowledge in a social setting that cannot be achieved alone, (c) direct guidance from more experienced workers, and (d) indirect guidance within both the physical and social environment. Thus, learning in social practices can be understood as qualities that are interdependently developed while working where the learners' involvement in real situations develops knowledge (Billett 2001a). As argued by Billett (2001b): "[l] earning through participation in work can be understood in terms of how the workplace supports or inhibits individuals' engagement in work activities and access to both the direct and indirect guidance" (p. 210). From that point of view, individuals' engagement affects the scope of action in combination with support and guidance from more experienced workers (Chan 2013). As learning and working can be seen as interdependent, participating and performing work-based tasks can be seen as an ongoing development of vocational competencies.

In this article, these three qualities will be elaborated as follow. First, the activities in which apprentices are engaged, can be seen as authentic tasks that are in line with the phase of production. The apprentices are also engaged in both low and high accountability activities, which could be defined in terms of high or low qualities of learning (Billett 2001a). As formally educated while undertaking workplace activities, the apprentices are driven by educational and workplace goals. The interaction between the kind of activities and the apprentice's personal goals and experiences thus becomes the moving target that can enhance vocational learning. Secondly, the interaction with more experienced workers forms and pushes the workplace process. This can be achieved in a range of ways (Billett 2013), and therefore, it is dependent on the specific workplace where the interaction with more experienced co-workers plays a significant role in the learning process (Andersson and Kalman 2010). The apprentices' vocational learning is formed and developed within differing contexts that provide unique interactions with more experienced co-workers. Nevertheless, the apprentices are all supposed to meet criteria that are stated in the description of goals. Third, the individuals' engagement in workplace activities constitutes and advances the development of vocational competencies (Billett 2001a). Apprentices' opportunities to engage in activities and interact with more skilled co-workers make development of vocational competencies possible. 
Consequently, the activities in which the apprentices are engaged will enhance or constrain learning. Therefore, the individuals' abilities to engage, interact and challenge the workplace will affect their ability to develop vocational competencies.

In relation to Billett's ideas of how learning is constituted, understanding what types of learning the apprentices can develop will be discovered from Ellström's (2001) idea of learning levels. Performing activities that can enhance or constrain learning are a part of everyday activities in workplaces. By having freedom in the learning environment, apprentices can develop different types of learning (Ellström 2001). These are called reproductive and productive learning, and are based on the freedom in "...the worklearning situation, specifically, the tasks to be performed, the methods and procedures to be used, and the results to be achieved" (p. 423). Understanding why the apprentices develop one level or the other is dependent on the scope of action within the activity.

\section{Research design}

This explorative study started by initiating interviews with post-secondary apprentices and later also a survey constructed from the description of goals. The interviews were between 35 and 55 min long and conducted with apprentices who are working in the construction industry. The apprentices were all working in different workplaces of different sizes, and had completed different numbers of hours in their workplaces, but they were all in the last stage of their apprenticeship.

Based on the information that emerged during the interviews, it became apparent that these apprentices were not aware of what they were supposed to learn according to the SCITB's description of goals. To further understand how activities in workplaces can constitute vocational learning, I created a survey based on the 64 goals. With respect to each of these goals, I posed three questions, and the apprentices graded each question on a 1-4 scale, where 1 represents "very little" and 4 "a great deal". The questions were: (1) To what extent do you perceive that it is important to have knowledge about the following goal? (2) To what extent do you perceive that you have knowledge about the following goal? (3) To what extent can your workplace contribute to developing the following goal? This strategy allowed me to examine how vocational learning by means of vocational education in workplaces could be developed through the apprentices' perceptions of learning goals, their own knowledge, and the activities provided by the different workplaces.

The apprentices were all males, which constituted $91.6 \%$ of the graduated upper secondary school students that participated in the construction programme 2013/14 (SCITB 2013). The apprentices addressed in this article had all completed a VET programme in order to become a woodworker in the construction industry. They were selected on the basis of having participated in the first part of this research project (Fjellström 2014, 2015). Based on the overall aim and purpose of this study, former students who did not proceed to apprenticeship were excluded, which reduced the number of participating apprentices from 15 to 11 .

\section{Analytical considerations}

I transcribed the interviews and categorised them into four key areas that emerged from the theoretical framework. These categories were: competence in the workplace, engaging in a task, educational expectations, and learning activities in the workplace. In a 
second analytical step, I analysed the results of the survey by summarising the answers (1-4) of each goal for each of the three questions. I discerned a pattern between the importance of a goal, how the apprentices perceived their knowledge of the goal, and the extent to which the workplace can contribute to developing such knowledge. As I conducted the survey on a relatively small sample $(n=11)$, the analytical steps in the survey were intended to identify patterns. In the third and final analytical step, I analysed the categorised interviews and the patterns from the survey in relation to the displayed aspects of a workplace curriculum and learning levels.

\section{Results and analysis}

The findings of this study will be presented through the lens of the theoretical framework under the sections Constituting vocational learning and Workplace activities.

\section{Constituting vocational learning}

By being a part of the building process and thus participating in workplace activities, the apprentices develop vocational competencies. This process is the moving target that is viewed as constituting workplace learning. As a result of the interaction between task performance and guidance from more skilled co-workers, the apprentices develop vocational competencies that correspond to workplace requirements. An apprentice, called Adam, explains how he learns:

Adam If someone is showing me how to perform a task or by trying and failing and redoing. Then it [the task] can be done right

Interviewer How much space is there to fail in a task when you work?

Adam They [the site manager and co-workers] know that I am an apprentice so they try to put me to the test. For example, I got to build a roof and that was mostly because I need to develop those skills. Based on what I have heard

Interviewer So was it stated: I [the co-worker] set you to this task although I am uncertain that you can perform it?

Adam Yes

Interviewer How did that feel?

Adam Well, it was a challenge but in the end there was a roof

Interviewer Was it correctly performed?

Adam Yes, it was. It actually was really good

Interviewer How can you know that?

Adam I made it according to the drawing

This quotation transcript not only reflects the intricacy related to the issues of possibility and trust of performing complex tasks. It also shows how the site manager and coworkers challenge the apprentice to perform new tasks. The apprentice performed this tasked correctly after being challenged by the site manager, who assigned the apprentice the task, and with guidance from more skilled co-workers. This authentic task corresponds to Andersson and Kalman's (2010) idea that learning from more experienced workers is crucial in the learning process. The performance of the task is an everyday activity with a conscious goal-directed motive, which Billett (2001a) argues constitutes qualitative learning. 
The apprentice stated that the task was correctly performed according to the drawing. In relation to that, all apprentices state that they have good opportunities to make decisions about the performance of tasks. This argument is related to methodological issues associated with performing a task rather than the result of the activity. Being able to plan and choose between methods promotes a productive learning environment (Fjellström 2014) in relation to Ellström (2001), who suggested that the freedom in the learning environment is associated with higher productive learning.

The activities provided in the workplace are not only about performing tasks. As part of the community, the apprentices learn and adopt competencies from more experienced co-workers. This is highlighted by Adam in the following extract:

Interviewer Can you give an example when you have learned something new? Adam No, not something, I believe that new things are learnt every day Interviewer Can you formulate in words what you feel that you can learn? Adam Well, I suppose that it is different techniques, how others perform a task, you walk past someone and see that he might hold a knife in a certain way when he cuts insulation or something like that

Interviewer So, by adopting something you see when passing a person, you can develop vocational competencies from that?

Adam Yes

Ben, on the other hand, argues that both indirect and direct guidance from more experienced co-workers is the driving force that enhances his vocational skills.

Interviewer But if you have to describe something that you want to learn. You talked about general knowledge of roofs, doors and windows

Interviewer How do you think you can develop such knowledge?

Ben Well, to work in a workplace that provides those kinds of tasks would be great and to have a person beside me who can explain and show me how to do them

Interviewer Is that important?

Ben $\quad \mathrm{Mmm}$, it is actually the most important. To have a person that both wants to and can teach and knowing what he is doing so I can do it right myself

\section{$[\ldots]$}

Interviewer

You say that you learn continuously, all the time, every day?

Ben Yes, I believe that you learn something new every day

Interviewer Is it something you achieve by yourself, or do you see how others perform?

Ben Well it is both. You can watch people perform tasks that you have never undertaken before and discover that "okay" that's the way you do the task. Or you just get better and can perform it faster. Then you think that you get better on this task or you learn something new. To me it has always been that I have learnt something every day, not always big things 
As both Adam and Ben describes it, the workplace can provide opportunities for vocational learning through indirect guidance from co-workers. By following or just walking past other skilled workers, the apprentice can develop vocational competencies. Learning through these kinds of situations is related to Billett (2001a) idea of learning through work, a workplace curriculum. The situational factors, as well as the activity in which someone engages, can help them "interact and interpretatively construct knowledge" (p. 21 ). This suggests that it is important that the environment provide not only opportunities to perform tasks, but also opportunities to interact with the situational factors that occur in the workplace. However, not all tasks are perceived as developing vocational competencies. Adam states that activities of low complexity do not enhance the development of vocational competencies.

Interviewer Can you give me an example of a task with poor opportunities for learning?

Adam For example, if you are cleaning the workplace, then you do not learn anything

Interviewer But if you see how someone is holding the knife at the same time as you clean?

Adam Well, then I learn something

Interviewer But cleaning is not something you learn from?

Adam No, I do not think so

$[\ldots]$

Interviewer Can you give me an example of a bad assignment or a bad environment for learning?

Adam For example cleaning, that's a bad task, you do not learn anything from that

Adam There are no problems associated with cleaning

Interviewer So, is it the challenges in the task that determine if it is a good or bad task?

Adam Yes, you get more motivated if there are more difficult tasks, then you have to think

Interviewer So, if I go back to insulation. Is that a good or bad task?

Adam A bad one, there are no problems to solve and you do not have to think

The idea that performing activities and having guidance from a more experienced co-worker enhances vocational learning is apparent, and reflects the apprentices' core argument about what actually constitutes vocational learning, i.e. performing complex tasks that challenges them to think. However, as Carl states below, learning is enhanced by more than just challenging tasks. Opportunities to make mistakes are also a way to develop vocational competencies. Hence, in relation to developing new and faster methods to perform a task, the mistakes can be assumed to be minor. 
Interviewer Could you describe a good learning environment or a good task to learn something?

Carl Yes, performing tasks that you have never done before and to do this alongside someone more experienced, that is a good way of learning. Performing tasks that you have never done before is a very good opportunity to learn, like things that challenge you, and that is when you learn the most. I prefer complex tasks that are hard because then I have the chance to try, make mistakes and learn from them

Performing activities with low complexity, that is, with no problems to solve, is perceived by the apprentice as not enhancing learning, whilst a "trial and error" approach toward complex tasks are perceived as a good way of learning. In relation to what Billett (2001a) suggests to be a good learning opportunity, these low complexity activities may constrain the development of vocational competencies. On the other hand, these low complexity tasks that are often seen as repetitive activities can enhance vocational learning because repetitive actions are always different and lead to learning (Lee and Roth 2005). However, as these findings indicate, the apprentices' engagement in these kind of activities is low, and the support and guidance from more skilled workers appears to be unnecessary. It seems likely that complex activities with the potential for problem solving are preferable for an environment that enhances productive learning.

As part of the workplace community, the apprentices are encouraged to perform tasks rapidly as a consequence of the payroll system; the faster one works, the more money one makes. This system encourages the apprentice, as well as the other workers, to develop new methods to perform tasks. As David explains it:

Interviewer The performance of a task is about using different methods. If you think back to when you started the assigned task, what were the possibilities for you to choose methods?

David Well if I have a better way of performing the task, of course I can try it, if it is better

Interviewer Are there any opportunities to change the way you perform the task during its progress?

David Yes of course, like now, first we went together and mounted boards. Then he [the co-worker] went ahead and I came after. It was much faster

Interviewer So it is all about changing and develop the method so it will go faster?

David Mmm

Or as Eric describes it:

Interviewer What options do you have to decide about the task and the methods for this assignment? Do you have options for that?

Eric Yes many, there are different methods depending on who is performing the task. I cannot say that I will do the same as the others. I do what I believe is the best. It is often heavy lifting for me so I do what I believe is best for my body and what I believe ends up with the best result 
As noted, both David and Eric are allowed to develop their own methods. David refers to the payroll system as a mediated artefact that enhance new solutions. Eric on the other hand refers to what he feels are better for his body and achieves a better result. The notion of having the authority to make their own decisions over methods is an idea expressed by all apprentices. Accordingly, this common characteristic encourages them to develop new methods to perform tasks faster. This is explained by Carl:

Carl As I said before, you have every option to decide for yourself. If I have the experience or knowledge to perform a task in a quicker way, then I do it whether or not someone else has told me to do it in another way. Or maybe I have been recommended to do it in another way. If I know a faster way to perform a task then I will do so, so yes I can definitely decide that for myself

Not only does the apprentices have to follow what others has said, they are also authorized to judge if they should do as they are told or use another strategy. Drawing on Billett (2001a) idea of a workplace curriculum, it is obvious that the apprentices' learning outcome is enhanced by the structures in the workplace that allows a freedom in the performance of tasks. A key component of enhancing productive learning (Ellström 2001) is the payroll system, which encourages them to develop new methods. Accordingly, the opportunities to do so increase their engagement and interaction, and therefore enhance their knowledge and skills from these situations. On the other hand, the payroll system that encourages a rapid performance of tasks can constrain learning in the sense that they can become specialized in a few narrow tasks. Nevertheless, opportunities to contribute and participate in developing their workplaces strengthen the apprentices' positions as full participants in their community (Billett 2001a; Lave and Wenger 1991). Drawing on the concept that learning and working are interdependent, it opens up the question of how learning and working can relate to stated goals.

\section{Workplace activities}

The lack of awareness about what the apprentices were expected to learn was apparent in all interviews, indicating that the description of goals has been overlooked, although the survey revealed that the apprentices perceived them as important. In relation to Q1 and Q2 in the survey ("To what extent do you perceive that it is important to have knowledge about the following goal?" and "To what extent do you perceive that you have knowledge about the following goal?"), the apprentices only graded one of the 64 stated goals as less important than their present knowledge. That goal related to the use of fire extinguishers, for which all the apprentices have competency certificates. Besides that goal, the apprentices consider themselves as having a sufficient level of knowledge in three goals (carry out prevention and firefighting; carry out insulation work with respect to heat, moisture, sound, and fire; and carry out internal lining with the following materials: sheets of wood, gypsum and fibre cement, and vertical and horizontal panels of wood). The apprentices are aware that there are 60 goals for which their competence and knowledge was below the level they considered necessary; however, they state that in general, they have competencies that relate to the goals (of 704 possible answers to Q2 in the survey, 32 are ticked as 1). Further, in Q3 ("To what extent can your workplace 
contribute to developing the following goal?"), it should be noted that for 62 of the 64 goals, the apprentices consider that the workplace can provide them with activities that can help them develop their desired level of knowledge. Although the apprentices are not aware of the learning goals, they develop competencies that correspond to them in many ways. Instead of relying on the learning goals that can be perceived as a paper product, the learning outcome is based on experiences where the apprentices learn from everyday activities in the workplace.

Despite an overall good idea of having vocational competencies that correspond to the required competence in their everyday work, they are aware that they have gaps that restrict them in their performance of tasks. This is related to the lack of qualifying certificates (e.g. for the operation of mobile platforms). To be able to perform these restricted tasks, they need the right certificate to operate the specific machine. Besides the lack of formal education, they have high expectations for the company to provide them with a broad education. This is exemplified by Adam, who says:

Adam Yes, of course something is missing, but it is hard to point it out what it is. But all are missing some competencies, so I want to get better in all areas. You cannot be skilled in everything

Interviewer But if you were able to learn something specific, what would it be?

Adam To be able to know the whole construction process. From the foundation to the finished house

Interviewer How do you think you could develop such knowledge?

Adam By being a part of it. See how it is made and try by myself. Like here, I have been here from the start

Interviewer So you are in that process now?

Adam Yes, you could say that

The apprentice has an idea that the developed vocational competencies should correspond to all stages in the construction process and, as stated, he reflects on being part of that process. This is a quite wide definition of required competencies and comprises everything that relates to building a house. In a reversed question about a specific competence that he wants to develop, the apprentice states that he does not know. Instead, he refers to the time sheet as a place where the competencies are articulated:

Interviewer You mentioned the time sheet

Adam Yes

Interviewer Do you know what it says in the time sheet?

Adam Foundation, waterproofing, cladding, yes about that

Or as David explains it:

Interviewer Do you know what vocational competencies you should develop during your apprenticeship?

David Yes, it is actually everything, you should have hours in every category on the time sheet

The apprentices are referring to the time sheet in order to understand what competencies need to be developed, which provides a narrow description of which competencies 
the apprentices should develop. In fact, the categories on the time sheet do not always correspond to the categories in the description of goals and include no qualitative learning goals. Further, the apprentice refers to categories that do not exist (but are referred to at the workplace), which provides an example of how the building process in the workplace overshadows the educational goals. Consequently, guidance and unique activities in the workplace (Billett 2001a) will form a learning outcome with or without learning goals.

\section{Discussion}

As this study has shown, apprentices follow a supervisor and/or co-worker and adopt their approaches to different tasks. This indicates that learning opportunities are related to the possibility to perform and be a part of activities provided in the workplace. Complex activities (above the apprentice's current skills) are "taught" and overviewed by supervisors and co-workers where apprentices are guided towards a correct result. By this approach, the apprentices' performances of complex activities often result in positive feedback by performing the task correctly, as a consequence of close supervision from more experienced workers. In opposite, non-problem oriented activities are considered not to develop competencies due to their low complexity. Therefore, the apprentices prefer activities with a high degree of complexity in order to develop vocational competencies. The apprentices are also assigned tasks that follow the phase of the construction, which the apprentices greatly appreciate. They state that following and understanding the building process is a key competence that can be developed only when apprentices being a part of that process. This argument corresponds to Billett's (2006) constitution of a workplace curriculum where the learner's development is related to participation in the community. However, these apprentices reflect about being full participants in their community at the same time as they state that they are apprentices in the process of education, with opportunities to choose tasks that enhance the development of vocational competencies. In relation to a workplace curriculum where the learner moves from low to high complexity activities (Billett 2001a), these apprentices reflect about participating fully and performing highly complex tasks although the apprentices have low accountability. In relation to a workplace curriculum, apprenticeship as it is displayed can be viewed as providing highly complex activities but not always with high accountability. The relationship between performing complex activities and having low accountability is related to the educational structure where the apprentices are learning and have assigned supervisors who guide and support them in their apprenticeship. Workplaces can thereby be viewed as offering diverse opportunities for vocational learning (Lyngsnes and Rismark 2011). The learning outcome is instead related to personal goals of wanting to learn, and activities that are provided within the environment.

Further, the finding shows that workplace contexts provide opportunities for apprentices, either on their own or in collaboration with others, to find solutions to enhance their performance of tasks. This freedom, or trial and error approach, will enhance a higher productive learning (Ellström 2001). Vocational learning is enhanced in relation to the interaction with more experienced workers, and by the opportunity for learners to develop their own solutions and problem solving activities when performing tasks. By learning from more experienced workers, the apprentices are able to go beyond their 
current competence (Andersson and Kalman 2010). Accordingly, the development of vocational competencies is related to opportunities to perform complex activities, as well as the freedom to develop new solutions and new methods to perform tasks.

As noted in this study, apprenticeship in an educational view can be seen from two perspectives. First there are the stated documents (i.e. a time sheet, description of goals and the planning and follow-up document). Except for the time sheet, the documents are rarely used, which opens up a discussion on the importance of these documents. It is noteworthy that the goals that are stated by STICB appear to be fulfilled in some way, but as revealed in this study, the apprentices were unaware of their existence. However, this does not exclude the possibility that the apprentice can gain such knowledge by performing workplace activities in a "fixed" time frame.

Second, the individual's perspective is highlighted in this study in terms of what the apprentices want to learn during their apprenticeship. It is noteworthy that none of the apprentices was aware of the goals that are stated by STICB. Instead, the apprentices referred to the categories on the time sheet, which does not include any learning goals. This indicates that fulfilling the $6800 \mathrm{~h}$ of work is central to the apprentices' idea of education. However, spending time at a construction site and ticking hours in a time sheet does not necessary equate with high quality learning in the profession. Instead, the apprentices' drive to become more rapid workers, because of the payroll system, enhances a higher form of learning.

Further, the performed activities in this study can be regarded as an example of what constitutes the development of a competent and skilled worker. As noted, one aspect that enhances productive learning is the apprentices' drive to contribute to production, that is, work faster. This is a factor that challenges them to advance new techniques for performing tasks that will develop productive learning. Another important aspect is their participation in complex activities that are perceived as being above their level of vocational skills. With direct guidance from more skilled co-workers and indirect guidance by listening to and observing others, complex tasks can be performed satisfactorily within a reasonable timeframe. Therefore, the kind of activities that are provided in the workplace in relation to the apprentices' own goals enhance vocational learning and thus the development of vocational competencies and skills.

In conclusion, this explorative study highlights a number of aspects that enhance vocational learning in post-secondary apprenticeship. First, vocational learning in workplace contexts is enhanced by workplace demands and activities that promote the apprentices to perform tasks they never have done before. Second, with close guidance from coworkers and a desire to earn more money (i.e. work faster), the apprentices are encouraged to develop new methods and perform tasks with high complexity that develop productive learning. Third, the apprenticeship, as described in this article, is guided by specified goals which outline the particular competencies that a construction worker with a professional certificate should have. These goals are important for the apprentices, but as revealed herein, workplace demands and activities combined with the apprentices' individual goals are the components that guide the apprenticeship. This opens up a wider discussion of how educational goals can be fulfilled in workplace contexts and the importance (or not) of educational goals in apprenticeship. Finally, both indirect and direct guidance by co-workers, in combination with workplace activities, can be viewed 
as the most important aspects of a successful vocational learning outcome. Drawing on these conclusions, it is clear that combining workplace demands and education goals is complex and based on various ideas (Zitter et al. 2016).

So, in a successful apprenticeship there are probably some aspects that are more important than others. In this article, four aspects have been identified as crucial in the constitution of vocational learning. First, the way the learner is guided by co-workers has shown to be crucial. Second, the trust from the management as well as co-workers to engage in complex tasks that challenges them to think is thus an important factor. Third, a close connection between performing tasks rapidly and the payroll system encourages the learner to advance task improvements and thus promotes vocational learning. Fourth, participating and being a part of the community where engaging in different tasks combined, contributes to becoming a part of the building process. So, this article has shown that the workplace is a contributor that is crucial in order to enhance vocational learning. Yet, this empirical study has also shown that personal goals affect the outcome. However, the inclusion of personal ideas of how vocational learning is constituted requires further empirical studies.

\section{Acknowledgements \\ Not applicable. \\ This manuscript is only submitted to this journal.}

Competing interests

The author declare that he has no competing interests.

Availability of data and materials

The dataset supporting the conclusions of this article are included within the article.

\section{Consent to participate}

Informed consent to participate in the study was obtained from all participants. This study is not a medical research and the data is not in conflict with the declaration of Helsinki.

\section{Consent for publication}

There are no details on individuals reported within the manuscript and the individuals displayed in text are fictitious to anonymize.

\section{Declarations}

This manuscript is an explorative study of post-secondary apprenticeship in Sweden which, in my opinion, contributes to the VET field. One reason for my choice of this journal is that I have earlier published an article here and this study is a follow-up study that I believe can be interesting for both the journal as well as the research field. Another reason is that the aim of this journal is suitable for me and others in the field and thereby an important place for publication.

Received: 19 December 2016 Accepted: 3 March 2017

Published online: 11 March 2017

\section{References}

Aarkrog V (2005) Learning in the Workplace and the significance of school-based education: a study of learning in a Danish Vocational Education and Training Programme. Int J Lifelong Educ. 24:137-147

Andersson A, Kalman H (2010) Reflections on learning in interdisciplinary settings. Int J Teach Learn Higher Educ. 22:204-208

Berglund I (2012) Att vara lärling i gymnasial lärlingsutbildning. [To be an apprentice in upper secondary apprenticeship education. In Swedish]. In: Henning Loeb II, Korp H (Eds.) Lärare och lärande i yrkesprogram och introduktionsutbildning. Lund: Studentlitteratur

Berglund I, Henning Loeb I (2013) Renaissance or a backward step? Disparities and tensions in two new Swedish pathways in VET. Int J Train Res. 11:135-149 (Routledge)

Berglund I, Lindberg V (2012) Assessment of vocational knowing: experiences from the Swedish pilot project with upper secondary apprenticeship 2008-2011

Billett S (2001a) Learning in the workplace: strategies for effective practice. Allen \& Unwin, Crows Nest

Billett S (2001 b) Learning through work: workplace affordances and individual engagement. J Workplace Learn. $13: 209-214$ 
Billett S (2009) Vocational learning: contributions of workplaces and educational institutions. International handbook of education for the changing world of work. Springer, New York, pp 1711-1723

Billett S (2013) Learning through practice: beyond informal and towards a framework for learning through practice. Revisiting global trends in TVET: reflections on theory and practice. pp 123

Billett S (2016) Constituting the workplace curriculum. J Curric Stud. 38:31-48

Chan S (2013) Learning through apprenticeship: belonging to a workplace, becoming and being. Vocat Learn 6:367-383 Ellström P-E (2001) Integrating learning and work: problems and prospects. Hum Resour Dev Q. 12:421-435

Eraut M (2009) Transfer of knowledge between education and workplace settings. In: Daniels H, Porter J, Lauder H (eds) Knowledge, values and educational policy: a critical perspective, vol 2. Routledge, Abingdon, pp 65-84

Fjellström M (2014) Vocational education in practice: a study of work-based learning in a construction programme at a Swedish upper secondary school. Empir Res Vocat Educ Train 6:2. doi:10.1186/1877-6345-6-2

Fjellström M (2015) Project-based vocational education and training: opportunities for teacher guidance in a Swedish upper secondary school. J Voc Ed Train. 67(2):187-202

Klotz V, Billett S, Winther E (2014) Promoting workforce excellence: formation and relevance of vocational identity for vocational educational training. Empir Res Vocat Educ Train. 6:6

Lave J, Wenger E (1991) Situated learning: legitimate peripheral participation. Learning in doing. Cambridge Univ Press, Cambridge

Lee Y-J, Roth W-M (2005) The (unlikely) trajectory of learning in a salmon hatchery. J Workplace Learn. 17:243-254

Lyngsnes K, Rismark M (2011) Learning for vocation apprentice participation in work practice. Online Submission. 8:165-176

Metso S, Kianto A (2014) Vocational students' perspective on professional skills workplace learning. J Workplace Learn. 26:128-148

SCITB (2013) Årsrapport. Byggnadsindustrins yrkesnämnd [The Swedish Construction Industry and Training Board. In Swedish]

Tynjälä P (2013) Toward a 3-P model of workplace learning: a literature review. Vocat Learn. 6:11-36

Virtanen A, Tynjälä P, Eteläpelto A (2012) Factors promoting vocational students' learning at work: study on student experiences. J Educ Work. 27:43-70

Zitter I, Hoeve A, Bruijn E (2016) A design perspective on the school-work boundary: a hybrid curriculum model. Vocat Learn. 9(1):111-131

\section{Submit your manuscript to a SpringerOpen ${ }^{\circ}$ journal and benefit from:}

- Convenient online submission

- Rigorous peer review

- Immediate publication on acceptance

- Open access: articles freely available online

- High visibility within the field

Retaining the copyright to your article

Submit your next manuscript at $\gg$ springeropen.com 